\title{
The Role of Content Strategy in Social Media on Brand Post's Popularity: a Case of Higher Education Institutions in Turkey
}

\author{
Assist. Prof., Dilek Penpece Demirer \\ Business Faculty, Adana Science and Technology University, Turkey
}

\begin{abstract}
The highly competitive higher education market has turned to branding as a solution for dealing with today's global challenges. One important tool of a sustainable brand strategy involves forming brand fan pages and attracting followers on social networking web sites. Implementing effective content strategy on brands' fan pages can help to form and foster relationships with the target group. Thus the aim of this study is to understand the role that content strategy in social networking web sites plays in determining the popularity of brand posts' created by leading higher education institutions in Turkey. Results indicate that the top ten higher education institutions in Turkey most commonly made posts representing the Text + image + link content type. The majority of posts to community members were created by the institutions themselves, involved university news and were primarily made on weekdays between noon and 18:00. Additionally, MANOVA analyses were conducted to investigate the role of various elements of content strategy on brand posts' popularity. Results indicate that content type, content agility, content context, posting type, and posting day significantly impact the number of likes, shares and comments, which are indicators of brand posts' popularity.
\end{abstract}

Keywords: Higher Education Institutions, Social Media, Brand Post Popularity.

\section{Introduction}

With little to no cost and constant growth, social media is able to bring together a large number of people from different backgrounds to create, modify, share and discuss Internet content (Keitzmann et al., 2011; Tafesse, 2015). According to the Digital, Social \& Mobiles' 2017 report, there are currently 2.789 billion active social media users all over the world, which means roughly 37 percent of the world's population is active on social media sites (We Are Social, 2017). There are 48 million active social media users in Turkey, which means approximately 60 percent of Turkey's population is active on social media sites (We Are Social, 2017). Although these numbers don't demonstrate the singular usage, they do undoubtedly indicate the tremendous marketing opportunities that social media offers.

Social media platforms serve as excellent vehicles for fostering relationships with customers. One specific way to do this is to form brand fan pages and attract followers on social networking web sites like Facebook, Twitter, Instagram etc. (De Vries et al., 2012). More than ever, users demand brand interactions on social media. In fact, Millenials (48.6\%) and Gen Xers (48.8\%) are twice as likely to follow a brand on social media as Baby Boomers (24.5\%) are (Sprout Social, 2017). So, creating brand fan pages and attracting followers have great potential for brands targeting Millenials and/or Gen Xers (ages 18-54). Marketers who wish to take advantage of these 'new forms of customer empowerment' (Cova \& Pace, 2006, p. ${ }^{* *}$ ) have to understand the attractiveness of brand-related interactions on social media sites for their target consumers (Muntinga et al., 2011).

Brand fan pages facilitate customers' relationship with the brand (McAlexander et al., 2002), and also provide information about the brand (Bagozzi \& Dholakia, 2002), thereby encouraging and accelerating its fame (Lipsman et al., 2012). On these brand fan pages, companies can make brand posts containing photos, videos, or other material (De Vries et al., 2012). Some brand posts attract many people and become increasingly popular, while others are ignored by fans (Chua \& Banerjee, 2015). Thus, brands face the challenge of developing and sharing content that builds and sustains the popularity of its posts on social media sites (Chauhan \& Pillai, 2013). Similarly, higher education institutions as brands have to design their digital content strategy in such a way that it expands its relationship with their audience. Since popular brand posts facilitates higher education institutions' connection with current and prospective students, employees, etc, the current study 
attempts to understand how content strategy in social networking web sites influences the popularity of brand posts created by leading higher education institutions in Turkey.

\section{Literature Review}

\section{Brand Fan Pages and Brand Posts Popularity}

Social media covers a wide range of platforms involving social networking sites (like Facebook), blogs (like Blogger or Wordpress), picture sharing web sites (like Flickr or Pinterest), video sharing web sites (like YouTube), wikis (like Wetpaint), social bookmarking web sites (like Delicious), content bookmarking web sites (like MERLOT), etc. (Penpece, 2013). Despite their similarities, the design of social networking sites differs considerably, making it essential to investigate these sites separately (Kietzmann et al., 2011; Trefzger et al., 2016). Facebook is currently the largest social networking site and the third most visited webpage after Google.com and Youtube.com (Alexa Analytics, 2017). Users on Facebook create their own profile and typically invite others into their networks (Ellison et al., 2011). A brand can also build its presence in the form of a "Page", a feature which was launched by Facebook in 2007 (Chauhan \& Pillai, 2013). Approximately 65 million business pages are active on Facebook in some way (Smith, 2017). Members or followers of such brand fan pages may perform a bridging function with other individuals (Palazón et al., 2015), since Facebook friends of those who already follow a given brand's Page can be considered potential followers of the brand fan page (Ellison et al., 2011). Because of this potential, this study focuses specifically on brand fan pages on Facebook.

Users simply have to 'like' the brand fan page, if they want to connect with a brand. Once this is done, a brand's posts are seen by users in their personal News Feed, where the largest portion of users' time is spent (Lipsman et al., 2012; Trefzger et al., 2016). So, it is highly likely that users will see the brand posts shared by fan pages. Brand post content is the instrument that stimulates interaction, since content-related activities reach, engage and establish a relationship with target audiences, thereby raising brand or company awareness (Penpece, 2013; Sabate et al., 2014). Successful content is adopted by fans. Thus, content reaches popularity, thanks to those fans' online behaviors (Sabate et al., 2014). People's behaviors on Facebook are not always the same (Kim \& Yang, 2017). Fans can reflect their thoughts, feelings, likes, and dislikes (Kietzmann et al., 2011). Besides brand fans in return interact with the brand posts through comments and shares (Chua \& Banerjee, 2015). Some studies have defined brand post popularity as the number of 'likes' and the number of 'comments' on a brand post (De Vries et al., 2012; Sabate et al., 2014; Tafesse, 2015), while others have focused on the number of 'likes', 'comments', and 'shares' (Cho et al., 2014; Chua \& Banerjee, 2015; Kim \& Yang, 2017). Although a simple click is enough for a 'like', behaviors such as 'comment' and 'share' require additional actions and may indicate a greater degree of commitment or cognitive involvement on the part of the user. Therefore, in order to determine what to show to users, Facebook assigns different weights to these behaviors, with 'like' weighted least and 'share' weighted highest. Thus, the strategic significance of each behavior may differ (Kim \& Yang, 2017), making it important to include all three of these behaviors when investigating brand post popularity.

The literature suggests that the brand posts popularity is driven by two factors, namely, customers' motivation (Muntinga et al., 2011) and the nature of brand posts, i.e., content type, context, agility, interactivity, vividness, and novelty (Chua \& Banerjee, 2015; De Vries et al., 2012; Kim \& Yang, 2017; Sabate et al., 2014; Tafesse, 2015). The content shared by the brands as a brand post follows a sequential process of perception creation. Then popular brand post builds positive attitudes and fall into favorable behavior about brand (Peng et al., 2004). In the competitive online environment, the content strategy followed by brands is critical. As such, the study attempts to understand the role of content strategy on brand posts' popularity as evidenced by the number of likes, comments and shares.

\section{Higher Education Institutions on Social Media}

The higher education market is now well established as a global phenomenon (Hemsley-Brown \& Oplatka, 2006). As a result of increasing competition in national and international environments and changing social contexts, higher education institutions are now driven by the need to market themselves (Alexa et al., 2012; Hemsley-Brown \& Oplatka, 2006). In today's complex and highly competitive marketplace, brand management has become increasingly important (Pinar et al., 2011). Thus, higher education institutions recognize the need to embrace a sustainable brand strategy (Pinar et al., 2011) and have turned to branding in order to deal with today's global challenges (Whisman, 2009). The importance of branding is acknowledged by higher education institutions in Turkey too, since they also operate in a highly competitive environment. The higher education market in Turkey has significantly developed during last decade with the number of universities in 
Turkey rising from 77 in 2006 to 185 in 2017 (www.yok.gov.tr). Higher education institutions in Turkey are aware of this sharp shift in the market and have responsed by using tactics such as branding to gain a competitive advantage and capture a part of the international market.

Marketers have also become increasingly aware of social media adoption and they are forced to find new ways to reach and interact with potential customers (Constantinides \& Stagno, 2011). In the light of these developments, it is expected that many higher education institutions will have to keep up with social media applications and social media users (Selwyn, 2011). Due to the high adoption rates of social media by those in the younger generation, engaging with social media is an extremely attractive branding tool for higher education institutions (Constantinides \& Stagno, 2011). According to the results of a Pew Research Center survey, young adults in America use social media, in particular Facebook, at high rates (Greenwood et al., 2016). Therefore higher education institutions can effectively connect and engage with their core target group and with various stakeholders, like current and prospective students, alumni and employees using social media.

In addition to assisting in the formation and maintenance of interpersonal connections, social media networking sites like Facebook can also guide students entering an unfamiliar social system, such as a higher education setting (DeAndrea et al. 2012). The millennial generation in higher education is a digitally native one with considerable social media experience (Wankel, 2009). Their use of online social networking sites not only facilitates the development of satisfying relationships with peers, but also fosters integrity and students' connection to their universities (Yu et al., 2010). Moreover, both online reviews/forums and social networking sites affect student's university search and choice at different levels (Lehmann, 2015), indicating that there is great potential benefit for higher education institutions if they can harmonize social networking sites with other branding tools. Higher education institutions in Turkey are increasingly using social networking sites as part of their programs. For example Boğaziçi University has a strong community of more than 115,000 members and 110,000 followers on Facebook and 64.000 followers on Twitter. Although there are numerous studies regarding the importance of social networking sites, very few of them pay attention to higher education institutions. Thus the purpose of this study is to fill this gap by investigating how content strategy on social networking web sites influences the popularity of brand posts created by leading higher education institutions in Turkey.

\section{Research model and hypotheses}

Relevant literature has mainly focused on how content strategy influences the audiences' response in terms of likes, comments and/or shares of brand posts (De Vries et al., 2012; Sabate et al., 2014; Tafesse, 2015). The key aspects of each post that determine the probability of interaction include content type, content agility, content context, posting type, and posting day. The customer's relationship with the brand, evidenced by the number of likes, comments, and/or shares, may be dependent on all these factors. Thus the research model was developed and shown in Figure 1.

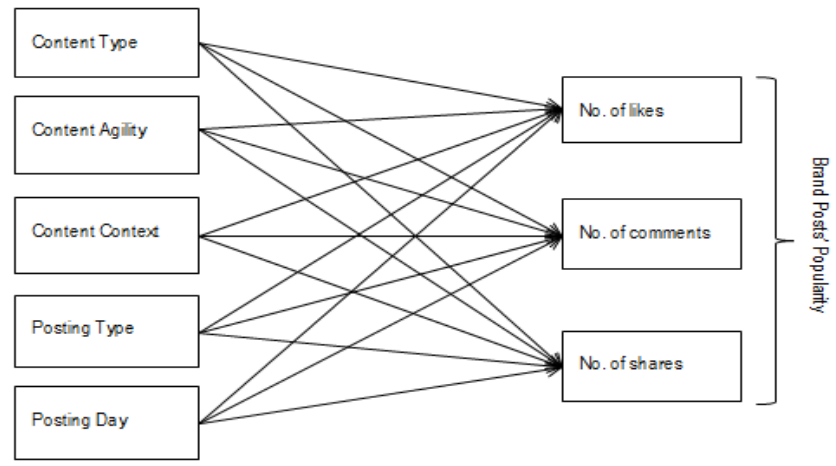

Fig.1. The conceptual model of the research

In this context, the key aspect of content strategy is the type of content. Some studies referred the content type as informational and entertaining etc. (De Vries et al., 2012; Tafesse, 2015). In this study, content type is referred to as text, image, video, link or a combination of them. The combination of text, image, video, and/or link is generally ignored by most of the studies. The literature suggests that content type including text, image, video, link etc. has significant impact on brand 
post popularity at different levels (Chauhan \& Pillai, 2013; Sabate et al., 2014; Kim \& Yang, 2017). Thus the following hypothesis is proposed:

H1. The content type has significant impact on number of likes, comments, and shares.

The audiences' response in terms of likes, comments and shares of brand posts is also affected by the time of day during which the post was made, defined in this study as content agility. When designing the posting schedule, identifying the customers' typical hours of activity is crucial (Sabate et al., 2014) so as to increase the probability of likes, comments and shares of the content. As such, the following hypothesis is proposed:

$\mathrm{H} 2$. The extent of content agility has significant impact on number of likes, comments, and shares.

The subject of the brand post is likely to influence audiences' response in terms of likes, comments and shares. In this study, the subject of the brand post is defined as content context. The following hypothesis is proposed:

H3. The content context has significant impact on number of likes, comments, and shares.

Brands in social networking sites can either create their own messages for members and non-members or they can share content that is generated by others. In this study, this is referred to as posting type. Relative to shared content, posts created by a company have been found to more positively impact the number of likes, comments and shares received (Kim \& Yang, 2017). Thus the following hypothesis is proposed:

H4. The posting type has significant impact on number likes, comments, and shares.

The day of the week on which the content is posted is called posting day. Previous studies show that most user activity on social networking sites occurs during weekdays (Golder et al., 2007), suggesting that those are the days during which customers are most likely to interact with brand posts. Hence, the following hypothesis is proposed:

H5. The posting day has significant impact on number of likes, comments, and shares.

\section{Methodology}

The higher education market in Turkey has rapidly developed during the last decade, making it necessary for higher education institutions to adopt a brand strategy. Engaging with social media as a higher education branding tool has great potential for higher education institutions. A brand fan page may perform a bridging function whereby members and nonmembers can have access to, and interact with, brand post. Thus content strategy is important in gaining brand post popularity. This study makes an attempt to contribute to the higher education literature by studying the influence of content strategy in social networking web sites on brand posts' popularity. Since Facebook is currently the largest social networking site, this study focuses on brand fan pages found on Facebook.

\section{Sample and Data Collection}

This study focuses on higher education institutions in Turkey. University rankings were used to identify the leading higher education institutions since it is presumed that higher-ranked institutions may more actively focus on content strategy on their brand fan pages. The Webometrics Ranking of World Universities was used here, as it offers ranking based on universities' web presence. The top ten higher education institutions selected based on their Webometrics Ranking are: Middle East Technical University (METU), İstanbul Technical University (ITU), Boğaziçi University (BOUN), Bilkent University (BU), İstanbul University (IU), Ankara University (AU), Hacettepe University (HU), Anadolu University (ANU), Ege University (EU), and Gazi University (GU) (see Annex 1).

The Facebook fan pages of these higher education institutions in Turkey were tracked for a period of one month, from July 1 to 31,2017 . The vast fan base of these brand pages are shown in Table 1. During this one-month period these institutions made a total of 340 posts (Table 1).

Table.1. The number of brand fans and posts

\begin{tabular}{|l|l|l|}
\hline & Number of posts & Number of fans \\
\hline METU & 32 & 120.061 \\
\hline
\end{tabular}




\begin{tabular}{|l|l|l|}
\hline ITU & 47 & 79.672 \\
\hline BOUN & 59 & 116.360 \\
\hline BU & 15 & 70.374 \\
\hline IU & 44 & 121.113 \\
\hline AU & & 69.370 \\
\hline HU & 39 & 81.050 \\
\hline ANU & 82 & 200.013 \\
\hline EU & 7 & 30.784 \\
\hline GU & 4 & 12.780 \\
\hline Total & 340 & \\
\hline
\end{tabular}

\section{Variables}

All Facebook posts were recorded and coded based on the elements of content strategy. In this study, brand post popularity is defined as the number of likes, comments, and shares on a brand post. Brand post popularity may be dependent on factors like content type, content agility, content context, posting type, and posting day. These factors are easily measurable and available free of cost. In this study, the content type variable was classified into the following 9 categories, which were adapted from Chauhan and Pillai's (2013) research: text only, image only, video only, link only, text + image, text + video, text + link, text + image + link, text + video + link. There is no clear agreement in the literature on the different temporal patterns proposed (Chauhan and Pillai, 2013; Sabate et al., 2014). In this study, content agility was assessed based on 4 six-hour time slots (00-06, 06-12, 12-18, 18-24) and posts were coded accordingly. Content context was classified into six categories adapted from Chauhan and Pillai's (2013) research: university news, alumni news, students' news, country and business news, education news and general engagement, (i.e., festival wishes, engagement with users about current affairs and so on). Posting day was divided into two categories based on Sabate et al.'s (2014) research: weekdays and weekends. Lastly based on Kim and Yang's (2017) research, brand posts were grouped into two categories: created and shared. The information related to these factors were gathered from each post on higher education institutions' fan pages that were made within a one-month period.

\section{Analysis and results}

First of all, reliability of the data was tested by intercoder reliability. Intercoder reliability measures the extent to which independent judges make the same coding decision in evaluating the characteristics of massages (Lombard et al., 2002). In order to eliminate the impact of the researcher's subjective values and judgments, two postgraduate students participated in the evaluation process. Reliability analysis produced a Cronbach's alpha score of about $86 \%$, indicating suitable intercoder reliability.

The content type shared by the top ten higher education institutions in Turkey are shown in Table 2.

Table.2. Content type results

\begin{tabular}{|l|l|l|l|l|l|l|l|l|l|l|l|}
\hline Content type & METU & ITU & BOUN & BU & IU & AU & HU & ANU & EU & GU & Total \\
\hline Text only & 0.0 & 2.1 & 1.7 & 0.0 & 0.0 & 27.3 & 7.7 & 0.0 & 0.0 & 0.0 & 2.4 \\
\hline Image only & 0.0 & 0.0 & 0.0 & 0.0 & 0.0 & 9.1 & 0.0 & 17.1 & 0.0 & 0.0 & 4.4 \\
\hline Video only & 0.0 & 23.4 & 0.0 & 0.0 & 0.0 & 9.1 & 5.1 & 1.2 & 0.0 & 0.0 & 4.4 \\
\hline Link only & 3.1 & 0.0 & 0.0 & 0.0 & 18.2 & 27.3 & 0.0 & 1.2 & 0.0 & 0.0 & 3.8 \\
\hline Text+image & 15.6 & 42.6 & 40.7 & 20.0 & 2.3 & 0.0 & 74.4 & 4.9 & 100.0 & 25.0 & 27.6 \\
\hline Text+video & 0.0 & 2.1 & 0.0 & 6.7 & 68.2 & 18.1 & 12.8 & 0.0 & 0.0 & 0.0 & 11.5 \\
\hline Text+link & 0.0 & 0.0 & 0.0 & 0.0 & 9.1 & 9.1 & 0.0 & 0.0 & 0.0 & 50.0 & 2.1 \\
\hline Text+image+link & 56.3 & 25.5 & 57.6 & 40.0 & 2.3 & 0.0 & 0.0 & 75.6 & 0.0 & 25.0 & 39.4 \\
\hline
\end{tabular}




\begin{tabular}{|l|l|l|l|l|l|l|l|l|l|l|l|}
\hline Text+video+link & 25.0 & 4.3 & 0.0 & 33.3 & 0.0 & 0.0 & 0.0 & 0.0 & 0.0 & 0.0 & 4.4 \\
\hline
\end{tabular}

The most common content type observed was Text + image + link with nearly 39 percent of the 340 total posts including content consisting of text, image and link. In particular, METU, BOUN, BU and ANU heavily used the Text + image + link content type. The second most preferred type is Text + image, which comprises nearly 28 percent of total posts. Almost 12 percent of posts have Text + video content, while just over 2 percent of posts have text only, and 3.8 percent of posts have link only content. Three kinds of content type - image only, video only, and text + video + link - represent the same percentage $(4.4 \%)$ of total posts. The Text + link content type is the least used by these institutions. The majority of observed content contain text since posts typically include introductory text that provides a brief introduction to the content and encourages community members to click on the image, video or link. Finally, none of the observed posts contain audio.

The content agility results of the sample are shown in Table 3.

Table.3.Content agility results

\begin{tabular}{|l|l|l|l|l|l|l|l|l|l|l|l|}
\hline Content agility & METU & ITU & BOUN & BU & IU & AU & HU & ANU & EU & GU & Total \\
\hline $00-06$ & 0.0 & 2.1 & 0.0 & 0.0 & 0.0 & 45.4 & 0.0 & 1.2 & 0.0 & 0.0 & 2.1 \\
\hline $06-12$ & 28.1 & 27.7 & 17.0 & 13.3 & 11.4 & 9.1 & 48.7 & 37.8 & 42.9 & 100.0 & 28.5 \\
\hline $12-18$ & 62.5 & 59.6 & 30.5 & 60.0 & 84.1 & 27.3 & 43.6 & 58.6 & 42.9 & 0.0 & 53.8 \\
\hline $18-24$ & 9.4 & 10.6 & 52.5 & 26.7 & 4.5 & 18.2 & 7.7 & 2.4 & 14.2 & 0.0 & 15.6 \\
\hline
\end{tabular}

The majority of posts, almost 54 percent, were made between noon and 18:00. Almost 29 percent of total posts were made between 06:00 and noon, while nearly 16 percent of total posts occurred from 18:00 to midnight. Overall, these institutions very rarely made posts between midnight and 6 a.m. ITU, AU and ANU made posts during all time periods.

The results for content context of posts made by the top ten higher education institutions in Turkey are shown in Table 4.

Table.4. Content context results

\begin{tabular}{|l|l|l|l|l|l|l|l|l|l|l|l|}
\hline Content context & METU & ITU & BOUN & BU & IU & AU & HU & ANU & EU & GU & Total \\
\hline University news & 75.0 & 74.4 & 72.8 & 86.7 & 84.0 & 72.7 & 76.9 & 74.4 & 85.7 & 25.0 & 75.9 \\
\hline Alumni news & 12.5 & 8.5 & 5.1 & 0.0 & 0.0 & 0.0 & 0.0 & 1.2 & 0.0 & 0.0 & 3.5 \\
\hline Students' news & 6.3 & 4.3 & 5.1 & 0.0 & 2.3 & 0.0 & 0.0 & 7.3 & 0.0 & 0.0 & 4.1 \\
\hline $\begin{array}{l}\text { Country and } \\
\text { business news }\end{array}$ & 3.1 & 6.4 & 3.4 & 0.0 & 2.3 & 9.1 & 0.0 & 3.7 & 14.3 & 0.0 & 3.5 \\
\hline Education news & 0.0 & 6.4 & 8.5 & 13.3 & 9.1 & 18.2 & 0.0 & 4.9 & 0.0 & 50.0 & 6.5 \\
\hline $\begin{array}{l}\text { General } \\
\text { engagement }\end{array}$ & 3.1 & 0.0 & 5.1 & 0.0 & 2.3 & 0.0 & 23.1 & 8.5 & 0.0 & 25.0 & 6.5 \\
\hline
\end{tabular}

Almost 76 percent of total posts were related to university news. This may be due to the month during which this study was conducted, since students in Turkey make university selections in July. As such, institutions may have prioritized content consisting of information about the institution and its departments, ranking attained by institutions, updates about universities and their achievements, various formal and informal events held at the institution and so on. Two kinds of content context - education news and general engagement, i.e., festival wishes, engagement with users about current affairs and so on - represent the same percentage (6.5\%) of total posts. Such forms of general engagement enhance the relationship between the brand and community members. Almost 4 percent of total posts were related to student news, while country and business news, and alumni news, both made up 3.5 percent of total posts. BOUN and ANU made posts representative of all content contexts.

The results for posting type are shown in Table 5. 
Table.5. Posting type results

\begin{tabular}{|l|l|l|l|l|l|l|l|l|l|l|l|}
\hline Posting type & METU & ITU & BOUN & BU & IU & AU & HU & ANU & EU & GU & Total \\
\hline Created & 56.2 & 70.2 & 62.7 & 66.7 & 72.7 & 45.5 & 100.0 & 30.5 & 100.0 & 25.0 & 60.9 \\
\hline Shared & 43.8 & 29.8 & 37.3 & 33.3 & 27.3 & 54.5 & 0.0 & 69.5 & 0.0 & 75.0 & 39.1 \\
\hline
\end{tabular}

Almost 61 percent of total posts included content that was created by institutions. HU and EU didn't use any shared content.

Results based on posting day are shown in Table 6 .

Table.6. Posting day results

\begin{tabular}{|l|l|l|l|l|l|l|l|l|l|l|l|}
\hline Posting day & METU & ITU & BOUN & BU & IU & AU & HU & ANU & EU & GU & Total \\
\hline Weekdays & 81.2 & 85.1 & 72.9 & 93.3 & 100.0 & 81.8 & 100.0 & 81.7 & 100.0 & 100.0 & 86.2 \\
\hline Weekends & 18.8 & 14.9 & 27.1 & 6.7 & 0.0 & 18.2 & 0.0 & 18.3 & 0.0 & 0.0 & 13.8 \\
\hline
\end{tabular}

Almost 86 percent of total posts were made by institutions during weekdays. IU, HU, EU and GU didn't share any content during weekends.

In the second stage of analysis, the influence of these various elements of content strategy on higher education institutions' brand post popularity was analyzed using a factorial MANOVA. The independent variables are nominal and the dependent variables (i.e., number of likes, comments and shares) are on an interval scale. Table 7 shows only the factors that significantly impact the number of likes, shares, and comments. Other interactions haven't been shown in Table 7 because they were found to be statistically insignificant with $p$-values greater than 0.05 .

Table.7. MANOVA results

\begin{tabular}{|l|l|l|l|l|}
\hline & & Value & F & Sig. \\
\hline Intercept & Pillai's Trace & 0.426 & 59.341 & 0.000 \\
& Wilks' Lambda & 0.574 & 59.341 & 0.000 \\
& Hoteling's Trace & 0.742 & 59.341 & 0.000 \\
& Roy's Largest Root & 0.742 & 59.341 & 0.000 \\
\hline Content type & Pillai's Trace & 0.910 & 13.165 & 0.000 \\
& Wilks' Lambda & 0.227 & 19.354 & 0.000 \\
& Hoteling's Trace & 2.813 & 27.978 & 0.000 \\
& Roy's Largest Root & 2.596 & 78.523 & 0.000 \\
\hline Content agility & Pillai's Trace & 0.384 & 11.830 & 0.000 \\
& Wilks' Lambda & 0.618 & 14.213 & 0.000 \\
& Hoteling's Trace & 0.617 & 16.359 & 0.000 \\
& Roy's Largest Root & 0.613 & 49.481 & 0.000 \\
\hline Content context & Pillai's Trace & 0.919 & 21.384 & 0.000 \\
& Wilks' Lambda & 0.217 & 32.644 & 0.000 \\
& Hoteling's Trace & 2.982 & 47.444 & 0.000 \\
& Roy's Largest Root & 2.760 & 133.577 & 0.000 \\
\hline Posting type & Pillai's Trace & 0.223 & 22.987 & 0.000 \\
& Wilks' Lambda & 0.777 & 22.987 & 0.000 \\
& Hoteling's Trace & 0.287 & 22.987 & 0.000 \\
& Roy's Largest Root & 0.287 & 22.987 & 0.000 \\
\hline Posting day & Pillai's Trace & 0.059 & 5.005 & 0.002 \\
& Wilks' Lambda & 0.941 & 5.005 & 0.002 \\
& Hoteling's Trace & 0.063 & 5.005 & 0.002 \\
& Roy's Largest Root & 0.063 & 5.005 & 0.002 \\
\hline
\end{tabular}




\begin{tabular}{|l|l|l|l|l|}
\hline Content type * Content agility & Pillai's Trace & 0.946 & 7.964 & 0.000 \\
& Wilks' Lambda & 0.164 & 14.233 & 0.000 \\
& Hoteling's Trace & 4.437 & 25.216 & 0.000 \\
& Roy's Largest Root & 4.291 & 74.167 & 0.000 \\
\hline Content type * Content context & Pillai's Trace & 0.499 & 4.025 & 0.000 \\
& Wilks' Lambda & 0.573 & 4.089 & 0.000 \\
& Hoteling's Trace & 0.625 & 4.146 & 0.000 \\
& Roy's Largest Root & 0.352 & 7.096 & 0.000 \\
\hline Content agility * Content context & Pillai's Trace & 0.921 & 10.723 & 0.000 \\
& Wilks' Lambda & 0.178 & 18.836 & 0.000 \\
& Hoteling's Trace & 4.085 & 32.495 & 0.000 \\
& Roy's Largest Root & 3.952 & 95.632 & 0.000 \\
\hline Content context * Posting type & Pillai's Trace & 0.483 & 15.461 & 0.000 \\
& Wilks' Lambda & 0.525 & 19.688 & 0.000 \\
& Hoteling's Trace & 0.891 & 23.636 & 0.000 \\
& Roy's Largest Root & 0.875 & 70.606 & 0.000 \\
\hline Content context * Posting day & Pillai's Trace & 0.210 & 3.652 & 0.000 \\
& Wilks' Lambda & 0.799 & 3.744 & 0.000 \\
& Hoteling's Trace & 0.240 & 3.818 & 0.000 \\
& Roy's Largest Root & 0.176 & 8.538 & 0.000 \\
\hline
\end{tabular}

The Box's test of equality of covariance matrices was found to be significant, as Box's M was 720.252 (Sig. 0.000). The Levene's test of equality of error variances for all dependent variables was significant. $F$ value which belongs to like of posts was 2.783 (Sig. 0.000). Additionally F values were 10.401 (Sig. 0.000) for share and 3.746 (Sig. 0.000) for comment. According to results, content type, content agility, content context, posting type, and posting day have significant impact on number of likes, shares and comments. Thus $\mathrm{H} 1, \mathrm{H} 2, \mathrm{H} 3, \mathrm{H} 4$, and $\mathrm{H} 5$ are all supported at 5 percent significance level. Hence it implies that probability of engagement with institutions' posts depends on content type, content agility, content context, posting type, and posting day. So all independent variables affect the brand posts popularity. Furthermore, the two way interaction between content type and content agility is significant. Besides content type interaction with content context is significant. The other two way interactions which are statistically significant at 5 percent significance level are: Content agility and content context, content context and posting type, content context and posting day. Five kinds of two way interactions affect the brand posts popularity.

\section{Conclusion}

The higher education market in Turkey has developed considerably during last decade. In response to these changes, many universities in Turkey acknowledge the importance of branding in gaining a competitive advantage and capturing a share of the international market. Engaging with social media as a higher education branding tool is an attractive strategy. One specific way to foster relationships with target group is to form brand fan pages and attract followers on social networking web sites like Facebook, Twitter, Instagram etc. To do so, higher education institutions as brands have to design their digital content strategy so as to effectively expand their relationship with their audience. With the help of popular brand posts, higher education institutions can connect with current and prospective students, employees etc. Higher education institutions face a challenge in forming their content strategy to build and sustain the popularity of their brand posts. Thus, this study attempted to understand how content strategy on social networking web sites influences the popularity of brand posts created by leading higher education institutions in Turkey. In this context, the key aspects of each post that comprise content strategy are content type, content agility, content context, posting type, and posting day. The number of likes, comments and shares represent the brand posts' popularity.

The Facebook fan pages of the top ten higher education institutions in Turkey were tracked for a period of one month, from July 1 to 31 . Observations indicate that some of these institutions did not actively use their brand fan pages and didn't reply to the questions asked by community members. Community members also expressed the need for English text on fan pages. On the other hand, the majority of higher education institutions used effective content strategy. During the onemonth observation period a total of 340 posts were made by these institutions, most of which represented the Text + image + link content type. Additionally, the majority of posts were made between noon and 18:00 during weekdays and included content created by the institutions themselves that dealt primarily with university news. To test the hypotheses, MANOVA 
analysis was conducted to show the influence of various elements of content strategy on brand post popularity in higher education institutions. According to results, content type, content agility, content context, posting type, and posting day have significant impact on number of likes, shares and comments. Thus $\mathrm{H} 1, \mathrm{H} 2, \mathrm{H} 3, \mathrm{H} 4$, and $\mathrm{H} 5$ are all supported at 5 percent significance level. So all independent variables affect the brand posts popularity. Finally five kinds of two way interactions which are statistically significant are: content type and content agility, content type and content context, content agility and content context, content context and posting type, content context and posting day. According to Chauhan and Pillai's research (2013) brand posts' numbers of like and comments were affected by content type like this study. But posting day and content context which have effect on numbers of likes and comments were not supported by them. This difference can have multiple causes. First it may be because posting day variable coded different from them. Second their sample just covers management collages' brand communities. Third these differences may be stem from cultural differences.

Some limitations of the current work need to be mentioned. For example, this study is focused solely on the top ten higher education institutions in Turkey, limiting the generalizability of these results. The study is also limited by the fact that only posts on Facebook fan pages were analyzed. Posts on other social media sites, like Twitter and Instagram should also be analyzed to determine how content strategies influence brand posts' popularity. Lastly, further research can be conducted in various countries to verify the findings and facilitate cross-cultural comparisons.

\section{References}

[1] Alexa Analitic, (2017). The Top 500 Sites on the Web http://www.alexa.com/topsites, Retrieved July 3, 2017.

[2] Alexa E. L., Alexa M., and Stoica C. M. (2012). "The Use of Online Marketing and Social Media in Higher Education Institutions in Romania", Journal of Marketing Research \& Case Studies, 1-9. Doi: 10.5171/2012.721221.

[3] Bagozzi, R. P., and Dholakia U. M. (2002). "Intentional Social Action in Virtual Communities", Journal of Interactive Marketing, 16(2), 2-21.

[4] Chauhan, K., and Pillai, A. (2013). "Role of Content Strategy in Social Media Brand Communities: A Case of Higher Education Institutes in India", Journal of Product and Brand Management, 22(1), 40-51.

[5] Cho M., Schweickart, T., and Haase A. (2014). Public Engagement with Nonprofit Organizations on Facebook, Public Relations Review, 40(3), 565-567.

[6] Chua A. Y. K., and Banerjee S. (2015). "Marketing via Social Networking Sites: A Study of Brand-Post Popularity for Brands in Singapore", Proceedings of The International MultiConference of Engineers and Computer Scientists (IMECS), 363-368, Hong Kong.

[7] Constantinides E., and Stagno M. C. Z. (2011). "Potential of the Social Media as Instruments of Higher Education Marketing: A Segmentation Study", Journal of Marketing for Higher Education, 21(1), 7-24.

[8] Cova B., and Pace S. (2006). "Brand Community of Convenience Products: New Forms of Customer Empowerment - The Case 'My Nutella The Community", European Journal of Marketing, 40(9-10), 1087-1105.

[9] DeAndrea D. C., Ellison N. B., LaRose R., Steinfield C., and Fiore A. (2012). "Serious social media: On the use of social media for improving students' adjustment to college", The Internet and Higher Education, 15(1), 15-23.

[10] De Vries L., Gensler S., and Leeflang Peter S. H. (2012). "Popularity of Brand Posts on Brand Fan Pages: An Investigation of the Effects of Social Media Marketing", Journal of Interactive Marketing, 26(2), 83-91.

[11] Ellison N. B., Steinfield C. and, Lampe, C. (2011). "Connection Strategies: Social Capital Implications of Facebook-Enabled Communication Practices", New Media \& Society, 13(6), 873-892.

[12] Greenwood S., Perrin A., and Duggan M. (2016). Social Media Update 2016. file:///C:/Users/pc/Downloads/PI_2016.11.11_Social-Media-Update_FINAL.pdf, Retrieved July 6, 2017.

[13] Golder, S., Wilkinson, D., and Huberman, B. (2007). "Rhythms of Social Interaction: Messaging Within a Massive Online Network", Proceedings of the Third Communities and Technologies Conference, Michigan State University, 41-66.

[14] Hemsley-Brown J., and Oplatka I. (2006). "Universities in a Competitive Global Marketplace: A Systematic Review of the Literature on Higher Education Marketing", International Journal of Public Sector Management, 19(4), 316-338.

[15] Kietzmann J. H., Hermkens K., McCarthy I. P., and Silvestre B. S. (2011). "Social Media? Get Serious! Understanding the Functional Building Blocks of Social Media", Business Horizons, 54(3), 241-251.

[16] Kim C., and Yang S-U. (2017). "Like, comment, and share on Facebook: How each behavior differs from the other", Public Relations Review, 43(2), 441-449. 
[17] Lehmann W. S. (2015). The Influence of Electronic Word-of-Mouth (EWom) on Collage Search and Choice, Doctoral Thesis, University of Miami.

[18] Lipsman A., Mudd G., Rich M., and Bruich S. (2012). "The Power of Like: How Brands Reach (and Influence) Fans Through Social-Media Marketing", Journal of Advertising Research, 52(1), 40-52.

[19] Lombard M., Synder-Duch, J. and Bracken, C. C. (2002). Content Analysis in Mass Communication: Assessment and Reporting Intercoder Reliability, Human Communication Research, 28(4), 587-604.

[20] McAlexander J. H., Schouten J. W., and Koenig H. F. (2002). "Building Brand Community", Journal of Marketing, 66(1), 38-54.

[21] Muntinga D. G., Moorman M., and Smit E. G. (2011). "Introducing COBRAs: Exploring Motivations for BrandRelated Social Media Use", International Journal of Advertising, 30(1), 13-46.

[22] Palazón M., Sicilia M., and López M. (2015). "The Influence of 'Facebook Friends' on the Intention to Join Brand Pages", Journal of Product and Brand Management, 24(6), 580-595.

[23] Peng K-F., Fan Y-W., and Hsu T-A. (2004). "Proposing the Content Perception Theory for Online Content Industry - A Structural Modeling", Industrial Management \& Data Systems, 104(6), 469-489.

[24] Penpece D. (2013). Dijital Içerik Pazarlaması, Karahan Kitabevi, Adana.

[25] Pinar M., Trapp P., Girard T., and Boyt T. E. (2011). "Utilizing the Brand Ecosystem Framework in Designing Branding Strategies for Higher Education", International Journal of Educational Management, 25(7), 724-739.

[26] Sabate F., Berbegal-Mirabent J., Cañabate A. and, Lebherz P. R. (2014). "Factors Influencing Popularity of Branded Content in Facebook Fan Pages", European Management Journal, 32(6), 1001-1011.

[27] Selwyn, N. (2011). Social Media in Higher Education. In A. Gladman (Ed.), The Europa World of Learning 2012, 1-9, Routledge, London. http://www.educationarena.com/pdf/sample/sample-essay-selwyn.pdf, Retrieved July 7, 2017.

[28] Smith C. (2017). By the Numbers: 90 Imazing Facebook Page Statistics (May 2017), http://expandedramblings.com/index.php/facebook-page-statistics/, Retrieved July 4, 2017.

[29] Sprout Social Survey, (2017). https://sproutsocial.com/insights/data/q1-2017/, Retrieved June 30, 2017.

[30] Tafesse W. (2015). "Content Strategies and Audience Response on Facebook Brand Pages", Marketing Intelligence \& Planning, 33(6), 927-943.

[31] Trefzger T. F., Baccarella C. V., and Voigt K-I. (2016). "Antecedents of Brand Post Popularity in Facebook: The Influence of Images, Videos, and Text", Proceedings of the 15th International Marketing Trends Conference, 18. Venice.

[32] Wankel, C. (2009). "Management Education Using Social Media", Organization Management Journal, 6(4), 251262.

[33] We Are Social, (2017) Digital Yearbook http://www.mikekujawski.ca/wp-content/uploads/2017/02/We-AreSocial-Digital-Yearkbook-2017.pdf, Retrieved June 30, 2017.

[34] Whisman R. (2009). "Internal Branding: A University's Most Valuable Intangible Asset", Journal of Product and Brand Management, 18(5), 367-370.

[35] Yu A. Y., Tian S. W., Vogel D., and Kwok R. C-W. (2010). "Can Learning be Virtually Boosted? An Investigation of Online Social Networking Impacts", Computers \& Education, 55(4), 1494-1503.

[36] http://www.yok.gov.tr/web/guest/universitelerimiz, Retrieved July 7, 2017.

\section{Annexes}

Annex.1. Ranking Web of Universities in Turkey 